\title{
A rare case of Systemic Lupus Erythematosus with Congenital Bifid Tongue
}

\section{Dr Veena Thimmappa ${ }^{1}$, Dr Neethu Mary $G^{2}$, Dr Narendra $G^{3}$ Dr Lakshmi Prabha Subhash ${ }^{4}$, Harshal $\mathrm{KL}^{5}$}

\author{
${ }^{1}$ Associate Professor, ${ }^{2}$ Postgraduate, ${ }^{3}$ Professor and HOD, Department of Dermatology \\ ${ }^{4}$ Professor and HOD, ${ }^{5}$ Research Associate, Cytogenetic Division, Department of Anatomy \\ Sri Siddhartha Medical College \& Research Centre, Agalakote, Tumakuru
}

DOI - 10.46319/RJMAHS.2019.v02i01.009

\section{Abstract}

Systemic Lupus Erythematosus (SLE) is an autoimmune disorder with multiple aetiology, presents with varied cutaneous manifestations and systemic involvement, primarily affects women in her child bearing age. Congenital bifid tongue is an anomaly due to nonfusion of the two lingual swellings. It can occur either as an isolated entity or in association with syndromes like Opitz G syndrome, Oral-Facial-Digital syndrome type I, Klippel Feil anomaly and Larsen syndrome or even as very rare feature in infants born to diabetic mothers. We present a case report of 23 year old female, a second child from a nonconsanguineous marriage with no significant antenatal or postnatal history, diagnosed of SLE. She had secondary amenorrhoea and hypothyroidism, examination revealed reduced secondary sexual characteristics, short stature, orbital hypertelorism and a bifid tongue which was present since birth. Recent studies suggest there is increased risk of autoimmune diseases particularly SLE development via the gene transmitted by X chromosome. It is also found that SLE patients are commonly associated with X chromosome polysomy. This case is unusual as the patient had multiple features suggesting genetic involvement, both SLE and bifid tongue is individually found to have genetic roots and till date there is no single case of SLE with a congenital bifid tongue in literature.

Keywords: Systemic Lupus Erythematosus, Congenital bifid tongue, autoimmune disease, X chromosome polysomy.

\section{Introduction}

SLE is a clinically heterogenous autoimmune disease of complex aetiology which primarily affects women in her childbearing age with varied cutaneous manifestations. Congenital bifid tongue is an anomaly due to nonfusion of the two lingual swellings. It can occur either as an isolated entity or in association with syndromes like Oral-Facial-Digital syndrome type I, Opitz G syndrome and Klippel Feil anomaly or as rare feature in infants born to diabetic mothers. ${ }^{[1]}$ A study in South India found prevalence of bifid tongue upto be $0.3 \%$.

Herein we present a 23 year old female with SLE, secondary amenorrhoea and hypothyroidism, reduced secondary sexual characteristics, short stature, orbital hypertelorism and a congenital bifid tongue.

\section{Case report:}

A 23 year old female, a second child from a nonconsanguineous marriage, with no significant antenatal or postnatal history, who is a known hypothyroid since past 3 years and with secondary amenorrhoea was referred to the Department of Dermatology with diagnosis of SLE. She presented with cough, oral ulcers, multiple joint pain involving knee, ankle and fingers and weakness since past one month. She gave history of recurrent episodes of skin lesions since past one year associated with burning sensation on sun exposure, predominantly on photoexposed sites. There was loss of appetite, polyarthralgia and weight loss for one month. She is neither on any regular medications nor gives history of any previous hospitalisation. Her developmental milestones were

Address for Correspondence:

Dr Veena Thimmappa, MBBS, MD

Associate Professor, Skin OPD, Sri Siddhartha Medical College, Tumkuru.

E-mail: veenathimmappa@gmail.com 
attained on time and she is a kindergarten teacher by occupation.

Examination showed pallor, multiple cutaneous hyperpigmented macules and patches predominantly on photoexposed sites, oral ulcers, nonscarring alopecia, hyperpigmented lunula of nails and bifid tongue. Further questioning revealed that it was present since birth and hence was further evaluated to rule out any congenital illness in family, gestational diabetes in mother, other facial/dental/limb anomalies. Systemic examination showed reduced axillary and pubic hair, flat chests and normal genitalia. Given the above clinical findings, diagnosis of SLE was made.
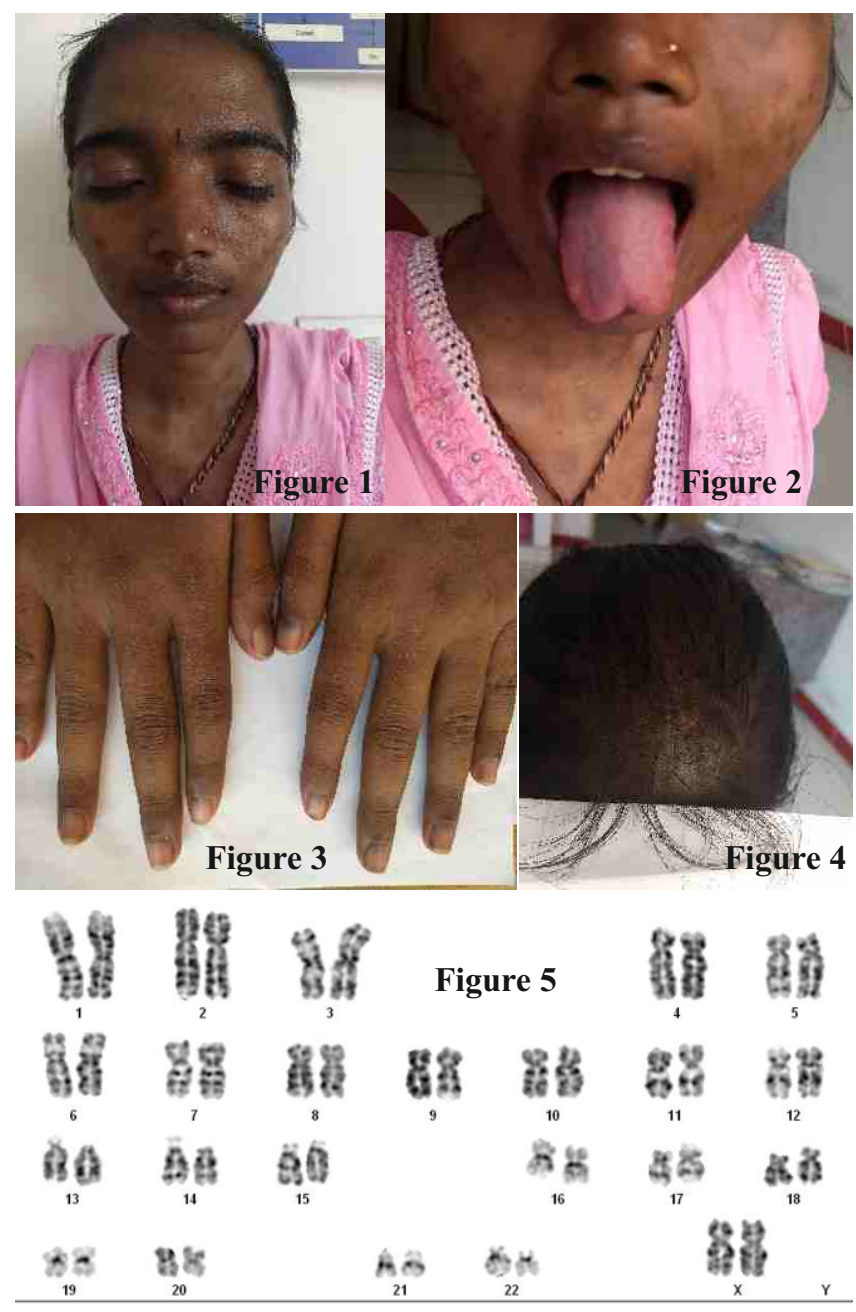

Figure 1. Hyperpigmented macules and patches

Figure 2. Bifid tongue

Figure 3. Hyperpigmented lunula of nails

Figure 4. Nonscarring alopecia

Figure 5. Normal karyotype $46 \mathrm{XX}$
Investigations were done which revealed macrocytic anemia, severely low haemoglobin $(4.6 \mathrm{~g} \%)$, lymphopenia $\left(2600\right.$ cells $\left./ \mathrm{mm}^{3}\right)$, thrombocytopenia $\left(99,000\right.$ cells $\left./ \mathrm{mm}^{3}\right)$, positive ANA. Chest and abdomen imaging were found to be normal. RBS was $357 \mathrm{mg} / \mathrm{dl}$ before starting steroids. Karyotyping to detect any chromosomal anomaly was done and was found to be normal.

She was managed with prednisolone $40 \mathrm{mg}$, hydroxychloroquine $200 \mathrm{mg}$ twice daily, tablet azathioprine $25 \mathrm{mg}$ twice daily and other supportive measures. She was also adviced strict photoprotection and was prescribed a broad spectrum sunscreen. Steroids were tapered eventually with improvement of symptoms and was discharged once the symptoms improved, for weekly followup.

\section{Discussion:}

SLE is an autoimmune disorder resulting in tissue damage caused by complement activation, autoantibody production and immune-complex deposition. The diagnosis was done based on the revised criteria by American College of Rheumatology which included photosensitive rash, oral ulcers, arthralgia, ANA positivity, lymphopenia and thrombocytopenia. Our patient has SLE with multiple features suggesting a chromosome involvement and also has a congenital bifid tongue. She also has hypothyroidism and diabetes mellitus.

SLE has 5-10 times more predilections in female than male. The exact reason for which is unknown. Studies suggest genes transmitted via the $\mathrm{X}$ chromosome can increase risk of autoimmune diseases in general including SLE. It is also found that SLE patients are commonly associated with $\mathrm{X}$ chromosome polysomy. ${ }^{[2,3]}$

The exact mechanism on how an abnormal $\mathrm{X}$ chromosome number might result in increased risk for lupus is not apparent. Lyon's hypothesis state "only one $\mathrm{X}$ chromosome in any given cell is transcriptionally active and the other gets inactivated by a process of methylation and histone deacetylation during the embryonic period, while around $15 \%$ of X-chromosome genes can autosomally escape this process and results in more than one active chromosome per cell. ${ }^{[4,5]}$ Thus suggesting female with X-chromosome polysomy results in gene over expression leading to immune 
disfunction via gene dosage effect and predisposed possibility of SLE patient with genetic abnormality ${ }^{[6]}$

Congenital bifid tongue is an anomaly due to nonfusion of the two lingual swellings. It can occur either as an isolated entity or in association with $\mathrm{X}$ linked syndromes.

This case is unusual as the patient had multiple features suggesting genetic involvement. Both SLE and bifid tongue are individually found to have genetic roots and till date there is no single case of SLE with a congenital bifid tongue in literature for further evaluation was carried out. Our patient did not fit into any of the syndromes completely and karyotyping was normal.

To conclude, though we suspected a chromosomal abnormality linking SLE and bifid tongue in the patient, we couldn't detect any. But, it is advisable to look for any sex chromosome polysomy in SLE patients, especially when they present with features suggestive of the former.

\section{Financial Support and sponsorship: Nil}

Conflicts of interest: Nil

\section{References:}

1. James AW, Culver K, Hall B, Golabi M. Bifid tongue: A rare feature associated with infants of diabetic mother syndrome. Am J Med Genet 2007;143A:2035-9

2. Smith-Bouvier DL, Divekar AA, Sasidhar M, Du S, Tiwari-Woodruff SK, King JK, et al. A role for sex chromosome complement in the female bias in autoimmune disease. J Exp Med 2008; 205(5): 1099-108.

3. M Slae et al. Female polysomy-X and systemic lupus erythematosus. Seminars in Arthritis and Rheumatism 43 2014;508-512

4. Sasidhar MV, Itoh N, Gold SM, Lawson GW, Voskuhl RR. The XX sex chromosome complement in mice is associated with increased spontaneous lupus compared with XY. Ann Rheum Dis 2012;71(8):1418-22.

5. Carrel L, Willard HF. X-inactivation profile reveals extensive variability in $\mathrm{X}$-linked gene expression in females. Nature 2005;434(7031):400-4.

6. Moraes LM, Cardoso LC, Moura VL, Moreira MA, Menezes AN, Llerena JC, et al. Detailed analysis of $\mathrm{X}$ chromosome inactivation in a $49, \mathrm{XXXXX}$ pentasomy. Mol Cytogenet 2009;2:20. 